Article

\title{
Seeking the Ideal of Universalism within Norway's Social Reality
}

\author{
Lydia Mehrara \\ Faculty of Social Sciences, Nord University, 8049 Bod $\varnothing$, Norway; E-Mail: lydia.mehrara@nord.no
}

Submitted: 10 October 2019 | Accepted: 12 February 2020 | Published: 18 March 2020

\begin{abstract}
How much inequality in policy instruments can a universalist welfare state tolerate in its pursuit of equity? This article reviews the nuances of universalism as a concept through examination of its meaning and application in Norwegian health policy, with a contextual focus on migrant maternal health in Norway. The Nordic welfare model is generous and dedicated to achieving equality through the universal provision of social services; however, there are increasing gray areas that challenge the system, invoking the conundrum of equality versus equity. Universalism is a central principle in Norwegian health policy, however changes in the socio-political environment have meant the concept as originally conceived requires a more nuanced articulation. Population changes in particular, such as a growing and diverse migrant settlement, present challenges for how to achieve the equality desired by universalist measures, while maintaining the equity demanded by diversity. This article uses an example of a Norwegian program that delivers maternal health services to migrant women to question the concept of universalism as a theoretical and practical construct, as historically and currently applied in Norwegian health policy. This example illustrates how healthcare as an organization functions in the country, and the role of its key players in adapting policy instruments to meet the Norwegian welfare state's universal policy aims. The scholarly contribution of this article lies in promoting a critical reflection on the evolving definition of universalism, and in contributing to a discussion on the need to retheorize the concept in Norwegian health policy to attain equity.
\end{abstract}

\section{Keywords}

diversity; health policy; maternal health; migration; Norway; universalism

\section{Issue}

This article is part of the issue “'Universalism' or 'Universalisms' in Social Policies?” edited by Monica Budowski (University of Fribourg, Switzerland) and Daniel Künzler (University of Fribourg, Switzerland).

(C) 2020 by the author; licensee Cogitatio (Lisbon, Portugal). This article is licensed under a Creative Commons Attribution 4.0 International License (CC BY).

\section{Introduction}

The Nordic welfare model is most generous and dedicated to achieving equality through the universal provision of social services, however there are divergences between its ideals and their application. This view is shared by Anttonen and Sipilä (2012) in their review of the Nordic welfare model, which asserts:

[The] model looks better on paper than in real life and it does not always perform according to its ideals. Many social programs are less universal than the ideology would suggest, and the policies that are strongly redistributive in intention often prove to be neutralized in the process of implementation. (Erikson, Hansen, Ringen, and Uusitalo, as cited in Anttonen \& Sipilä, 2012, p. 28)
There are increasing gray areas in this welfare system that invoke the conundrum or paradox of equality versus equity, and the discrepancy between the ideal of universalism in policy versus its implementation in practice.

Universalism is a central principle in Norwegian health policy, however changes in Norway's sociopolitical environment, and the evolution of the welfare state since its inception, have meant that the concept as originally conceived requires a more nuanced articulation. The notion of universalism is faced with the challenge of diversity, particularly that of ethnocultural diversity brought on by a relatively new and growing segment of the Norwegian population, immigrants. Indicators of differing health outcomes among this group compared to the local population have led to discussions concerning issues of equity in a system founded upon a desire to attain equality. Responding to these challenges 
has not been easy or without consequence, thus leading to this article's primary analytical question: How much inequality in policy instruments can a universalist welfare state tolerate in its pursuit of equity?

This article examines the meaning and application of universalism in Norwegian health policy as both a theoretical and practical construct. It starts with a history of universalism and its adoption in Norway followed by an overview of Norwegian health policy in relation to immigrant women and their access to maternal health provisions. The argument presented here concerns the paradox of equality and equity as a manifestation of universalism in Norwegian policy. It therefore suggests a more nuanced approach to maternal immigrant health within Norwegian health policy. This task begins with a brief historical account of Norway's adoption of universalism. The next section offers a contemporary overview of Norwegian health policy and illustrates its enactment through the specific example of a local maternal health initiative for immigrant women, whilst addressing the definitions and relationships between the concepts of immigration, diversity, equality, equity and universalism. In light of this example, the following section theoretically explores the concept of universalism, distinguishing its nuances and shortcomings, as compared and linked to the policy and practice nexus of universalism in Norway. A discussion section merges the contextual analyses and the theoretical perspectives of the two preceding sections. In doing so, it reflects critically on the paradox of equality and equity brought forth as a challenge to universalism which Norwegian health policy needs to face in response to growing diversity in the population. This section presents an in-depth review of the divergences between the application of universalism as a concept in policy aims (theory), and in policy instruments (practice) in Norwegian health policy. Finally, the article concludes by examining possibilities of an articulated reiteration of universalism in Norwegian health policy as a resolution to the presented challenge.

\subsection{A Historical Account of Universalism and the Development of the Welfare State}

The welfare state as a national institution in many countries is relatively new, having emerged in the mid twentieth century in response to societal upheavals. In order to achieve its institutional welfare objectives, a series of social policies, some of which already existed in smaller scales, were gradually implemented by states and thus expanded to cover their entire populations. Norway's adoption of a welfare regime followed a general pattern in developed Western countries having instituted several social reforms during the previous century. The British welfare system, often considered to be the start of a recognized welfare state, emphasized the need for social protection against many of the social ills, and the provision of social insurance as protection built on previous systems, such as had already existed in such places as
Germany and Norway. Such state-based protection systems were considered to be universal and their provisions were to apply to all of society irrespective of individual circumstances, because the improvement of society was the ultimate aim. Individual circumstances and meeting of particular needs could either be incorporated within the universal provisions or addressed separately as general eligibilities. While the Norwegian and British welfare systems differ, as will be described briefly below, universalism, as an ideology emergent from the idea of universally provided services, was a key factor in social provision, including health.

How and why Norway came to adopt universalism as a policy direction is open to different interpretations. For Kuhnle and Hort (2004), the many initiatives of social insurance in Nordic countries before and during the twentieth century paved the path for the adoption of universalism. They identify four central positions in support of universalism: community building, risk exposure, human dignity-i.e., the Universal Declaration of Human Rights in 1948-and economic and bureaucratic efficiency-i.e., eliminating means-testing (Kuhnle \& Hort, 2004). For them, these offered the obvious foundations for institutionalizing the principle of universalism across the state. Kautto (2010) instead maintains, it was the particularities of the Scandinavian political, demographic, and cultural climates of the time that led to what has since been labelled the Social Democratic Welfare State system in Scandinavia. Given the largely homogenous populations of Nordic countries then, combined with a common history of social policy development increased the likelihood for the successful adoption of universal ideas. Universalism was justified in this welfare model because it supported national cohesion or unity and increased the functional capacity of citizens. It is beyond the scope of this article to trace these trajectories and conditions in depth, but universalism in Norway owes its particular regime to this history, which has shaped and affected public and social policy since. This article will explore the implications of this broad concept in Norway's welfare institution today.

\section{Universal Public Health in Norway Today}

Norway has one of the most comprehensive social policy models extending to health policy, with the universal application of provision assuming equal access and benefit. Decentralization is an operational mechanism to ensure efficient distribution, with the State maintaining a regulatory role and local governments being primary providers. Figure 1 illustrates this organization. Here maternal health services are highlighted as this will serve as an example for analyzing universalism as a policy aim (theory) and instrument (practice) in the subsequent section.

All non-hospital based primary healthcare are the responsibility of municipalities (Figure 1). This division of responsibility grants municipalities autonomy and thus a 


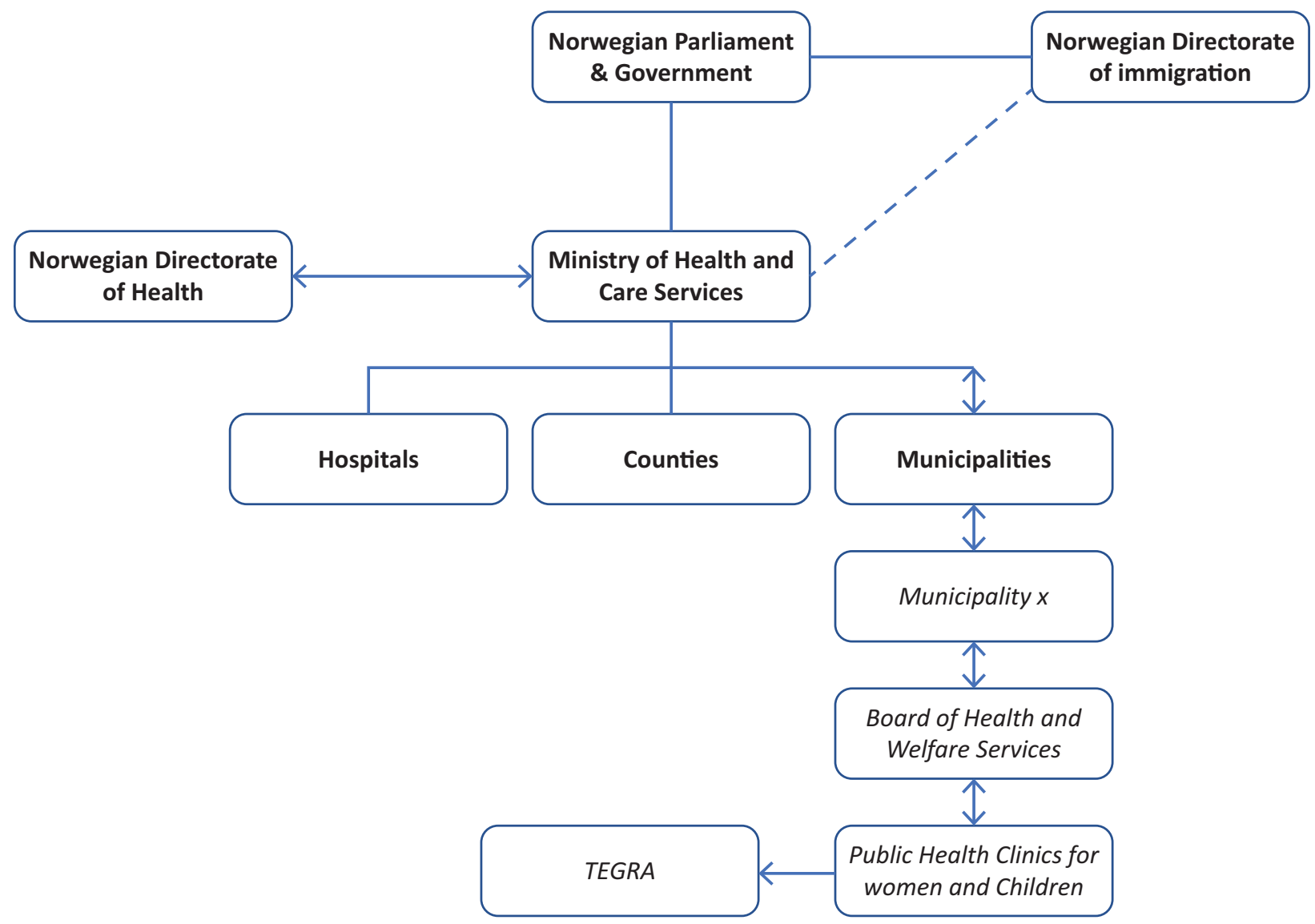

Figure 1. Organization of health services in Norway. Figure adapted from Ringard, Sagan, Saunes, and Lindahl (2013, p. 17, Figure 2.1).

degree of flexibility in tailoring service provision within the framework of national guidelines and standards to best meet the particular needs of their local populations. This governance system assumes that primary service provision operates most efficiently at the most local level possible.

Despite attempting maintenance of the welfare state's egalitarian and universalistic ideals through this healthcare distribution model, the responsibility of local municipalities to provide non-hospital based reproductive healthcare means that service provision may vary across the country. Various settlement patterns across the country further complicate the system, as do the challenges of growing ethnocultural diversity resulting from increased immigration in Norwegian society. To contextualize this issue, migrants made up less than two percent of Norway's total population in the 1970s (Vassenden, 2010). Whereas in 2019, persons with immigrant backgrounds, i.e., "persons born abroad with two foreign-born parents and four foreign born grandparents, in addition to persons born in Norway with two foreign-born parents and four foreign-born grandparents" (Statistics Norway [SSB], n.d.) henceforth referred to as migrants, comprise nearly eighteen percent of Norway's population (SSB, 2019). As migration is not explicitly recognized as a determinant of health in Norwegian health policy, where the focus mostly concerns access, there have been various responses to $\mathrm{mi}-$ grants' needs across Norway.

\subsection{Migration, Diversity, and the Issue of Equity}

Norway's relative ethnic homogeneity until recently has meant issues of cultural diversity being a necessary target for policy, such as in health, have not been prominent. As described earlier, the development of the Nordic welfare state and the adoption of universalism as a hallmark feature of this model were driven by a collective, postWar sense of unity and desire for equality, facilitated by the homogeneity of their populations. Though positive and progressive in intention, an unexamined ideology of universalism can exclude those who do not conform to the model's homogenic definitions. The dearth of research from a policy to practice perspective in Norway indicates that policy makers and implementors are not cognizant of how people from different sociocultural backgrounds experience universalism in its current blanketed approach. This topic will be elaborated through the example of maternal health services in the following subsections.

Keeping with the need for further research, there now exists an imperative to retheorize universalism and 
its coexisting nuances as currently applied in health policy to account for the emerging sociocultural diversity. Increasing indicators associated with the growing national migrant population that emphasize the challenges and shortcomings of health policy illustrate this need (Attanapola, 2013; Dahl, 2009; Munthe-Kaas, Bidonde, Nguyen, Flodgren, \& Meneses, 2018). This is not only a Norwegian issue; multiple European studies highlight the differences in health outcomes, help seeking and differential access patterns of their migrant populations despite their right to health services (Darj \& Lindmark, 2002; Dejin-Karlsson \& Östergren, 2004; Ny, 2007; Rechel et al., 2011). Consequently, this presents the challenge of how to achieve the equality or sameness in opportunity desired by universalist ideals of Norwegian social policy whilst ensuring the equity or fairness demanded by Norway's diversity. These challenges are not limited to migrants, but also involve other underrepresented or unrepresented groups within Norwegian society. Immigrant women and the issue of maternal health services is one specific example referenced by this article. The following two subsections lay the contextual foreground for this debate in order to problematize and later address the multifold intricacies of the concepts of equity and equality.

\subsection{Maternal Health Provisions for Immigrant Women}

Despite the entitlement of all pregnant women to free maternity care regardless of their legal status (Helsenorge, 2019), the discrepancy between equality versus equity, resultant from a blanketed yet indeterminant approach to universalism, is evident in maternal health provision for immigrant women. Despite the universalist assumption of equal rights to health services enabling health equity, equal opportunity and health outcome is not warranted for all immigrant women. Differences in the utilization of prenatal and antenatal care by immigrant women in comparison to nonimmigrant women, and a higher prevalence of complications and unfavorable birth outcomes among this group, indicate these disparities (Nørredam \& Krasnik, 2011; Reeske \& Razum, 2011). This demonstrates that there are issues of poor access, which must be considered from both institutional and individual perspectives. Institutional access barriers may be due to poor institutional knowledge and resources to address migrant women's health needs, dissemination of information in hard to reach immigrant communities, and perhaps even that of health center proximity. In combination with individual factors embodied by migrant women, such as cultural differences, language barriers, or education level, these can lead to different health seeking patterns, and subsequently to poorer health outcomes for both mothers and infants. Such circumstances are poorly addressed by universalist or state level policy and provisions. In keeping with the decentralized policy framework presented in Figure 1, action has been taken by some munic- ipalities. One such health promotion program offered by a municipality is presented below to facilitate the discussion surrounding the analytical question of how much inequality in policy instruments or treatment can a universalist welfare state tolerate in its pursuit of equity. The information for this case which comes from a previous study by this author (Mehrara, 2017), is utilized like other investigative material in this theoretical article: to illustrate and analyze, but not to empiricize, the enactment of universalism in Norway.

\subsection{Example of a Local Health Initiative for Immigrant Women}

In the early 2000s, a group of primary maternal health service providers working in a Norwegian municipality with one of the highest concentrations of immigrants in the country designed a program named TEGRA (short for inTEGRAtion; see Stavanger Kommune, 2016). This development was in response to both the challenges they faced in working with migrant women, and the disparities of maternal and child health outcomes they saw in this group over time in comparison to the Norwegian population. After several years of voluntary operation, the project was incorporated formally at the municipal government level and has since received public funding.

TEGRA, which initially began to address the issue of female genital mutilation, has expanded its scope and aims to address broader topics of health promotion aimed at a more diverse group of immigrant women (Mehrara, 2017). TEGRA now offers free comprehensive and linguistically inclusive pre- and post-natal workshops, specifically designed for immigrant women. These workshops play an important role in promoting the integration of immigrant women into Norwegian society by developing their system knowledge, a type of knowledge required for them to understand and navigate the health and welfare system. Not only providing information around pregnancy, childbirth and motherhood in Norway, they support and empower immigrant women to gain an understanding of and access to the available resources. Furthermore, the workshops create a space for network building for these mothers. These actions accumulate and lead to better understanding, trust and use of not only the health system but other social services, and ultimately the integration and overall wellbeing of immigrant women. An additional program objective is to increase the cultural competency of healthcare professionals and other service providers working with immigrant women and their families through education, training and topic specific discussions both at the local and national levels (Helsesøstre, 2007).

This free local health initiative for immigrant women runs in parallel and in addition to the state-run health services in this municipality. The success of TEGRA both in overall qualitative measures of satisfaction from service users, and quantitative reports on the improvement of health and birth outcomes among the immigrant popu- 
lation, reaffirm its necessity. TEGRA's success has gained the praise of both local and national service providers. The municipality's formal recognition of TEGRA shows the incentive and need for such programs, where services are targeted toward specific population groups in Norwegian society who are otherwise overseen by standard distribution protocols. This demonstrates that a degree of selective universalism as described by Carey and Crammond (2017) and discussed further in section three, is well received and required. A similar program has recently been adopted by another Norwegian municipality, where it too has gained popularity. Together, these indicate that the decentralized health governance system allows for some local flexibility toward developing equitable approaches to healthcare.

The downside to this localized response is that due to differences in resources, demographics and responses between municipalities, this approach can inadvertently deepen inequality in the country and within the system. While women in certain municipalities can benefit from extended support programs, women in other Norwegian localities where such tailored programs do not exist, have the complex task of navigating the healthcare system as their own responsibility, which may impact their use and trust of the health system in the long run. This approach to maternal health provision within Norway's universal frame of health policy, leads into this article's critical discussion of whether this system's overarching ideology of fairness actually translates to equity in practice. Before taking this discussion further, it is important to clarify what is meant by equity and equality in the context of diversity and universalism.

\subsection{Equity and Equality}

Teasing out equity from equality is a complex task. Depending on context, the two are given various definitions. Within the context of this article, equality refers to a sameness in entitlement or right to a standard set of available health services, whereas equity in health is considered a critical aspect of accessibility, and it differs from equality in that it "concerns fairness" (Nørredam \& Krasnik, 2011, p. 67). Furthermore, "equity is the absence of avoidable or remediable differences among groups of people, whether those groups are defined socially, economically, demographically, or geographically" (WHO, n.d.). Applying an equality focused policy to the distribution of health services, i.e., granting access to healthcare as a statutory right to all eligible residents in Norway, neither ensures equality in the ability of beneficiaries to access and use services, nor guarantees equality in outcome. An equality-oriented approach, though seemingly fair, overlooks that this equal right needs to be mobilized by its beneficiaries to become an opportunity through which they can benefit from healthcare services to their fullest potential, and to attain equal outcome. While equality implies a right, equity implies both equal opportunity and equal outcome; hence, a policy following an ideology that is meant to promote equality does not necessarily offer distributive justice or equity in practice. This system-oriented argument is not to insinuate that equality of opportunity and outcome in health are one-dimensional transactions independent of individual factors, or that all migrants have poor health outcomes. As already explained, access to health and consequently health-seeking behavior are multidimensional; therefore, equality of opportunity and outcome do not depend only on the health system, but also on the life course or previous experience of the migrants. This analysis, however, focuses on the role of healthcare as an institution in Norway, because though it may not be the only factor enabling equality of opportunity and outcome, its recognition and response to diversity makes it a significant contributor to broadscale change, and to achieving equity.

The assumption underlying the blanketed approach to universalism in Norway, or its equality focused social and health policy, implies that everyone's needs can be addressed by granting them the same right to healthcare and to a same set of general provisions. Entitlement to a right does not necessarily contribute to fairness because it does not take into consideration the subset of individual or institutional factors that may limit the mobilization of an opportunity. It is therefore important to consider the element of equity in health policy to recognize diverse needs. Though achieving absolute equity is a utopian idea, an equity-oriented policy, conscious of and proactive about the differences among people's needs can lay the foundations for more equitable healthcare system and more equal outcomes.

The recognition of differences is fundamental in order to mobilize a system that provides equal right to healthcare, to a system that offers distributive justice. Awareness of the individualistic needs existent in an ethnoculturally diverse population within the collectivist frame of Norwegian political ideology is essential for promoting equity. The case of TEGRA provides one example of how primary service providers recognized the need to address diversity within the universal approach of healthcare in Norway. Nevertheless, the relationship between equality or equity is more complex than a simple binary of a right and opportunity or outcome. Neither explore the intricacies of diversity within the scope of universalism, in this case, the diversity of immigrant women's maternal health needs in Norway's universal health system. Moreover, the issue goes beyond the scope of health equity, though it is the example through which the concept of universalism is analyzed in this work. The issue of blanketed universalism extends to a general question of inclusion and integration of immigrants in Norwegian social policy. To claim universal equality whilst not recognizing ethnocultural diversity, or how people from different backgrounds experience universalism, reinstates a monocultural view of privilege which may contradict the Norwegian ethos of social democracy, and also contribute to segregation within the population. 
This of course is one lens through which the fairness of this universal health system can be analyzed. Another important perspective that the enactment of healthcare in practice should be critiqued from is through questioning whether its current approach to health equity can be problematic. More specifically, can this degree of governmental decentralization, and the autonomy of "streetlevel bureaucrats," itself be viewed as problematic?

TEGRA is an initiative developed in response to a demand, wherein an effort has been made to recognize the diverse maternal health needs of immigrant women. Absence of this program or similar ones, incorporated or accommodated at the central level of health policy in Norway, leaves the responsibility of targeting services and ensuring universalism in practice to primary service providers, such as midwives and health nurses. These actors can be referred to as "street-level bureaucrats," a concept coined by Lipsky (1980), which refers to those actors who use their discretion in amending policy practice: "Street-level bureaucrats in the Nordic states are supposed to implement universalist policies and statutory services within the context of local, democratic institutions" (Vike, 2018, p. 250). In the case of maternal health services for immigrant women in Norway, street-level bureaucrats play a key role in addressing policy shortcomings, by devising grass-root initiatives that tailor general policy recommendations to address the more specific needs of service users. The autonomy of street-level bureaucrats in their role as the 'nuts and bolts' of the policy practice nexus in Norwegian health policy has been fundamental to the continuous expansion and adaptation of social policy to meet the diverse needs of the population. However, this raises a question of whether this is an appropriate and sustainable way to address the challenges of diversity facing Norway's universal social policy.

This approach to universalism certainly has some benefits for health equity, such as providers being able to address the specific needs of service users, however it is simultaneously problematic. Designating street-level bureaucrats to bridge the gaps between the ideal of universalism in policy, to its enactment through practice in their social realities, does not eliminate gaps in central policy and its theoretical underpinnings. Rather, it provides a 'band-aid' solution, where the consequences of this imbalance are most visible, i.e., in municipalities with a high concentration of immigrants. With respect to maternal health initiatives such as TEGRA, the needs of immigrant women in more remote parts of the country without such initiatives are not as explicitly attended to, consequently imposing the service users with a larger burden of personal responsibility to navigate the healthcare system and beyond. Meanwhile, its availability in other regions privileges those immigrants within a specific geographic proximity. This links the argument back to the issue of equality and equity discussed earlier and calls for an examination of the meaning and application of universalism as a concept in Norwegian health policy. The following section dissects universalism as a concept, in order to provide the theoretical framing for the discussion to follow of whether there is a discrepancy between the ideal of universalism and its application in Norway's social reality in section four.

\section{Contemporary Deconstruction of Universalism in Norway}

Thus far, the article has focused on the inception of universalism and its application in Norwegian health policy. Some issues were raised with respect to the concept's meaning and relation to diversity, equality and equity, using an example of a local health initiative to both problematize and illustrate the different facets of the argument. This section expands its focus to deconstructing the meaning of universalism as a concept and retheorizing its application in Norwegian health policy. In doing so, it offers a critical review of the contemporary implications of universalism in order to position the analysis of universalism in Norway.

To start, universalism can be comprehended as both a simple or a complex concept; where its meaning has evolved from its traditional sense as a redistribution mechanism, to its meaning being context, time, location and discipline bound. When the concept of universalism was coined, its vague definition allowed for interpretation and thus for different stakeholders to appropriate it to suit their purposes at different times (Anttonen, Haikio, \& Kolbeinn, 2012). Through the evolution of its application and more scholarly interest in its variance, the concept has been given multiple meanings: "Rather than referring to some single abstract principle, universalism can be seen as a multidimensional concept that refers to a set of principles" (Stefánsson, 2012, p. 42). Below, views of the concept are represented from three different perspectives, beginning with a theoretical overview, going onto an operational presentation, and finally a comparative analysis of universalism as a distribution mechanism.

\subsection{Theoretical Overview}

Universalism as a theoretical concept is contested. Anttonen et al. (2012, p. 37), explain universalism as a theoretical dichotomy in which, 'universal' refers to a mechanism of redistribution and the type of welfare state, whereas 'universalism' refers to a "particular kind of social ideology." They exemplify this referring to its adoption in the British welfare model as the nature of benefits, and in the Nordic model as a spirit and ideology. Stefánsson (2012) argues instead that from a theoretical perspective, universalism refers to person-state relationships and social inclusion, whereas in a procedural sense it describes a distributive process(es). A simple reiteration of these views can instead maintain that universalism can be used to define policy aims or instruments, one outlook emphasizing a theoretical ideology and the latter practicality or processes of distribution. This distinction is exemplified in Table 1. 
Table 1. Universalism as policy aim compared to universalism as policy instrument.

\begin{tabular}{lll}
\hline Theoretical dichotomy & Universalism of policy aims & Universalism of policy instruments \\
\hline Central dogma & Universalism as a social ideology & Universalism as an operational principle \\
Focus & $\begin{array}{l}\text { Person-state relationship and social } \\
\text { inclusion (Stefánsson, 2012) }\end{array}$ & Mechanism of distribution (Stefánsson, 2012) \\
Effect & Consequentialist (Anttonen et al., 2012) & Procedural (Anttonen et al., 2012) \\
Example & Nordic universalism & British universalism \\
\hline
\end{tabular}

Universalism, a complex theory, cannot only be described as a mutually exclusive dichotomy, as presented in Table 1. For the universalism of policy instruments to come about, some underlying universalist ideology is prerequisite; likewise, for the translation of universal policy aims, policy instruments require awareness of and operation within a universalist frame. One might argue, rather, that the theory of universalism exists on a continuum. Though universalism forms the underpinning ideology of welfare policy in Norway, Norwegian universalism cannot be distilled to emphasize only an ideology, or the universalism of policy aims and of social inclusion. Universalism in Norway is also an applied policy approach or instrument for the redistribution of social and welfare services across the country. In a comparative example, the UK policy framework predominately presents universalism as a redistribution mechanism (Anttonen et al., 2012). Though a degree of universal ideology exists, the focus in the UK is on the application of universalism as an operational principle for some services such as primary education and healthcare, as opposed to a political ideology encompassing all public services as in Norway.

This variation in characterization also continues in the application of universalism, where varieties of universalism coexist both at an institutional level and at the practice level, and where "each dimension of universalism is a matter of degree not a dichotomy" (Anttonen et al., 2012, p. 189). Scholarship thus emphasizes that the universality of programs lies on a spectrum of universalism in both its theoretical ideology and its practical ap- plication. The following subsection therefore examines different types of universalism on this continuum.

\subsection{Operational Presentation}

To begin, Carey and Crammond (2017) provide an operational definition of universalism by dividing the concept into two broad institutional approaches based on how a government defines service provision, i.e., general or specific universalism. They describe 'general universalism' as a type of universalism where "flat-rate benefits are applied to all, irrespective of citizenship, class, means or need" (Carey \& Crammond, 2017, p. 304); whereas 'specific universalism' "supports free, universal availability of public services...to all on the basis of citizenship (though it does not necessarily guarantee universal access)," and "goes beyond flat-rate benefits in an attempt to redress existing inequalities" (Carey \& Crammond, 2017, p. 305). This is presented in Table 2.

The concept of selectivism can be applied within the framework of specific universalism, where the definition and scope of social benefits still tend toward broad definition based on a general concept of common good. Selectivism differs from residualism, whereby benefits are not only targeted to the poor, and is concerned with targeting services to population subgroups based on their needs. Some scholars argue that like residualism, selectivism does not fit within the framework of universalism because it is not all inclusive and thus discriminatory (Anttonen \& Sipilä, 2012). However, Carey and

Table 2. Operational overview of universalism as institutional approaches. Adapted from Carey and Crammond (2017).

\begin{tabular}{lll}
\hline Institutional approaches & General universalism & Specific universalism \\
\hline Rationale & $\begin{array}{l}\text { Protection of the population through } \\
\text { flat-rate benefits for everyone } \\
\text { Examples }\end{array}$ & $\begin{array}{l}\text { Universal social benefits to promote social } \\
\text { rights and social equality }\end{array}$ \\
Eligibility & Infectious disease control and sanitation & Public health insurance; public schools \\
Limitations & $\begin{array}{l}\text { Can only be applied in certain contexts } \\
\text { where the need triumphs above social, } \\
\text { political and economic barriers. }\end{array}$ & $\begin{array}{l}\text { Though there is more targeting, this type of } \\
\text { universalism still too general as it overlooks } \\
\text { sociocultural diversity and does not } \\
\text { therefore guarantee equal benefit within } \\
\text { society because it impartially favors } \\
\text { predominant social norms. }\end{array}$ \\
\hline
\end{tabular}


Crammond (2017, p. 304) argue for selectivism within the frame of universalism, explaining that "while universalism is regarded as a precondition of equality, it does little to promote redistribution and ignores existing inequalities." Thus, a degree of targeting or tailoring of services is required within a proportionate application of universalism to achieve health equity (Carey \& Crammond, 2017; Carey, Crammond, \& de Leeuw, 2015).

Selectivism is further subdivided into two categories, positive and negative (Carey et al., 2015; see Figure 2). Within a universal system, positive selectivism addresses the specific needs of particular groups through a decentralized model of welfare governance, where without any means-testing schemes, "state funded agencies embedded in communities are sensitive to, and can cater for, difference and diversity" (Carey \& Crammond, 2017, p. 305). Examples include programs, such as that of TEGRA illustrated in section two, that offer additional support within a public system to specific groups based on their needs. Negative selectivism however, "targets the provision of services and assistance on the basis of individual means (i.e., using means-testing) within a universal framework" (Carey \& Crammond, 2017, p. 305). This type of targeted universalism is often argued to be stigmatizing because it is susceptible to defining disadvantage on the basis of means testing. Finally, there exists the notion of particularism, which is at the opposite end of general universalism on the impartiality scale, as it profoundly emphasizes recognition of all types of diversity in society and consumer choice in tailoring government services. In other words, particularism is a very individualized system and the antithesis of universalism's collectivist underpinnings, with a high degree of targeting at the cost of a high degree of impartiality or eligibility criteria. Figure 2 below represents these different distribution methods relative to their degree of impartiality and targeting.

The breakdown of universalism as theoretical and operational constructs, or as policy aims and policy instruments, sets the analytic framework for investigating universalism in Norwegian health policy. Bringing together this conceptual framework with the example of TEGRA in section two, the types of universalisms at play in Norwegian health policy can be extrapolated by analyzing the nuances surrounding this issue's policy and practice nexus.

\section{Discussion}

This article has examined the policy and practice of universalism in Norway, posing the question: How much inequality in policy instruments can a universalist welfare state tolerate in its pursuit of equity? This section synthesizes the various discussions on the topic thus far and reflects on both the adoption and application of universalism in Norway, offers suggestions for retheorization of the concept, and makes recommendations for policy and further research.

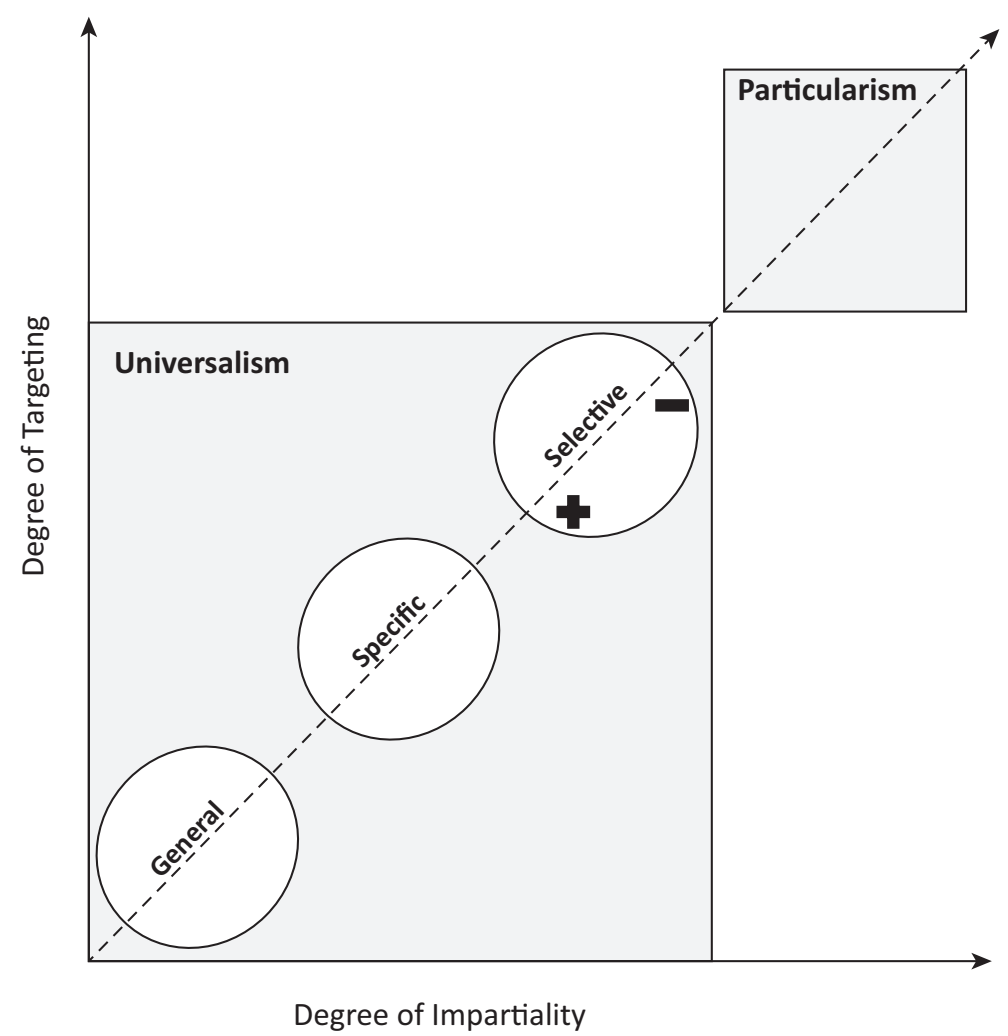

Figure 2. Universal benefit distribution based on degrees of impartiality and targeting. Adapted from Carey and Crammond (2017). 


\subsection{Reflections on Norwegian Universalism}

Norway's approach to social policy aims strongly resonates with a generic notion of universalism, particularly, that of specific universalism, where the only eligibility criterion is legal residency status (Table 2). This simplistic and all-encompassing definition traces back to the principle's historical foundations. Meanwhile, in the implementation of its policy instruments, i.e., governance of distribution, and particularly healthcare, Norway's decentralized approach allows for a great degree of malleability. This enables different localities in the country to adopt various methods of redistribution and service provision within the frame of the central general government guidelines. Targeted programs that operate in addition and or in parallel to standard services for at risk or minority populations, who due to various factors may otherwise be impeded from benefiting from these services, are included here.

There are of course benefits to geographic localized targeting, the major one being cost savings, i.e., not spending on programs that are not uniformly needed across the country. The second benefit of this approach is the autonomy and the flexibility it gives municipalities and street-level bureaucrats to design and offer relevant programs within the scope of national requirements, as programs can be continuously launched and altered to meet local demands. This ties in with another benefit of small-scale local projects, their ability to circumvent bureaucratic hurdles.

Nevertheless, there are less favorable aspects to this approach. To begin, though needs may vary within a diverse population, the fact that many social and health needs are universal cannot be discredited; therefore, it is flawed to assume that a health disparity linked to ethnocultural diversity is only specific to a single municipality. It may be that some social challenges or needs are more visible or frequent in some parts of Norway due to demographic variables such as its immigrant population, average age, unemployment status, and more; yet they cannot suppose the regional specificity of these problems. Secondly, local programs may be cost effective in the short run; however, such needs often persist and grow in a population, and thus in the long run, and in lieu of systematic programs collectively targeting the common needs of a particular populations, the burden will fall on individual service providers and service users, resulting in the consumption of more time and resources. Likewise, in the absence of a standardized audited protocol, the effectiveness of the latter scenario may vary extensively from one provider to another. Hence, not only can this be financially costly to the system, it can also challenge the service providers and affect the quality of care they provide.

The selectivist approach to universalism, adopted to address the gaps inherent to this policy aim in the enactment of policy instruments, brings about yet another set of challenges. The case of TEGRA presents a 'posi- tive selectivist' approach to targeting of services to immigrant women, wherein "positive selectivism aims to provide additional services and resources for certain groups on the basis of needs (e.g., without means testing)" by being more sensitive to difference and catering to diversity (Carey \& Crammond, 2017, p. 305). Although at first glance, this seems like an equitable approach to distribution, even within this framework, the needs of beneficiaries are potentially defined homogenously through the lens of those in power, the mostly ethnically Norwegian primary care providers. Programs developed based on what the service providers assume a specific group of the recipients' needs to be can unconsciously counter their positive intentions of addressing different needs of the population (Carey \& Crammond, 2017). This argument also questions the degree of choice that can be tolerated in a universal welfare system, and hence distilled into the paradigm of new public management; nevertheless, this article's scope is limited to merely signaling these possibilities.

\subsection{Recommendations for Policy and Research}

In asking whether the systematic targeting of services should be incorporated at the national level within the frame of universal social policies, it is argued that local initiatives targeting universal benefits through positive selectivist measures, should be audited by the municipality. If they are running as a formal function locally, they should then be audited by national authorities such as the Directorate of Health, and they should meet certain standards to ensure service users' satisfaction, or contribute to statistical improvements of dependent variables, such as better maternal and birth outcomes. Furthermore, there should be more dialogue between service providers and policy makers as to why these programs are beneficial, and whether and how they could be incorporated nationally to benefit more people. TEGRA's example shows that such programs respond to a common need or demand in addition to health promotion and preventive care, and that participation in such programs can improve the cultural health capital of immigrant women. Shim $(2010$, p. 1) defines cultural health capital as "the repertoire of cultural skills, verbal and non-verbal competencies, attitudes and behaviors and interactional styles, cultivated by patients and clinicians alike, that, when deployed, may result in more optimal healthcare relationships." Participation in such programs expands benefits beyond a specific service by giving service users the knowledge, tools, and skills to navigate the system, and to mobilize and optimize the healthcare opportunities to which they are entitled. The question remains of why the systematic targeting of services, especially in cases where they have been tried and tested, is not incorporated nationally.

To summarize this conceptual review of universalism, the principle of universalism is loosely defined in Norwegian health policy, and in its current form, it can- 
not deliver to its ideals in practice. The principle, as it stands today, is a vague amalgamation of its nuances as a theoretical ideal from the time of its inception in the Norwegian welfare state, and of its locally defined and applied definitions as a principle for practice: "The conceptual history of universalism would appear to be closely linked with the making of social policy" (Anttonen \& Sipilä, 2012, p. 37). While providing the foundations for constructing a welfare system with social democratic ideals and reflecting a collective interest in a common good, there are now greater expectations from the modern welfare state, and the needs it must cater to are wider in scope and variety than at its inception. Socio-political changes, population growth, aging population and more ethnocultural diversification impose new challenges on the universal policies of the welfare state, specifically on what those policies ought to imply beyond their theoretical shell of policy aims, and in practice as well.

In Norway, the burden of bridging the gap between the ideal of universalism in policy, versus its enactment at the service delivery level, is currently left to public service agents. However, without the formal recognition of these shortcomings at the national level, the paradox of the equality demanded by universalism and the equity demanded by diversity also remains.

Through providing 'equal' treatment or access to different groups, the thought in many universalistic welfare states, such as Norway, at least from a historical standpoint that remains deeply embedded in policy today, is that equality will result. However, "welfare scholars argue that many states which have been described as 'universal,' exclude certain groups by virtue of viewing populations as homogenous" (Carey \& Crammond, 2017 , p. 304). This indicates a problem with the sameness in treatment, as in the model of specific universalism adopted in Norwegian health policy, as assuming an impartial solution to provision can be insensitive to some people's needs and ability to access services, especially those whose needs fall outside the margins of the dominant society and culture. As stated earlier, though the core principle of universalism is considered prerequisite to achieving equality, in its application, when differences among individuals and their needs are overlooked, it consequently results in countering its objectives of equal distribution or opportunity (Carey \& Crammond, 2017). To therefore ensure equality, differences must be considered and, with that, "to be sensitive to differences in need, Dworkin's theory of equality argued that individuals must be treated differently" (Carey \& Crammond, 2017 , p. 304). In the case of migrant maternal healthcare in Norway, notions of universalism in the distribution of maternal healthcare may obscure social diversity, because notions of good practice and understandings of diverse needs may vary across and within different localities.

Nevertheless, targeting services and redefining universalism with a felt-tipped pen in order to make it truly 'universal,' both in theory and practice, leads to the im- portant question, posed by Carey and Crammond (2017, p. 304) of "how much diversity should policies and programs seek to encompass." More specifically, this leads to the central analytical question of this article: How much inequality in policy instruments can a universalist welfare state tolerate in the pursuit of equity?

Perhaps the answer to these questions lies beyond universalism, or perhaps it requires a more nuanced articulation of universalism. The reconsideration of social policy, including health policy in Norway does not require a total redefinition, rather it requires a rethinking and clarification of the conceptualization of universalism and its implications. Most certainly, "universalism is not a panacea" (Anttonen et al., 2012, p. 187) and there will always be shortcomings. But fine-tuning the theory, and its consequences in practice, can reduce some of the discrepancy the concept carries between equality and equity in Norwegian social policy. Despite some gray areas, Norwegian health policy remains one of the most comprehensive and successful health systems in the world. However, to uphold this status, it requires a more systematic and pragmatic approach to dealing with change, especially concerning its increasingly diverse ethnocultural population. The emphasis in Norwegian health policy should therefore go beyond the eligibility issues, i.e., specific universalism (Table 2), to how to be more inclusive and efficient in addressing the different needs of the population it covers, i.e., through positive selectivism. There needs to be recognition at the national level that, "citizenship is an equal status for all citizens but affects them differently" (Stefánsson, 2012, p. 62), which is true of universalism as well in that not everyone experiences it the same way. This primarily requires the problematization of this issue and its shortcomings in policy. Secondly, the engagement of service users from the population's minority groups and their collaboration with service providers and policy makers can enhance the understanding and accommodation of their particular needs.

The key for answering the article's analytical question is not in the invention of a barometer to measure the capacity of universalist policy aims in tolerating inequality of treatments through universal policy instruments in the pursuit of equity, but in exploring whether there is at all a capacity within this social policy framework to dissect the nuances of universalism as a concept in theory and in practice. This is undoubtedly a mammoth task, but through the theoretical analysis of health policy in Norway, and the concept of universalism, this article means to initiate this process and spark further discussion and research.

\section{Conclusion}

This article reflected on the concept of universalism in social policy, to challenge its orthodox notions of idealism and equality with the questions of change and diversity, within the frame of health equity in Norway. Labeling 
Norway's health system as universalist, prompted a dissection of the concept as adopted and applied through an example of its enactment to explore the implications of universalism in this system, and whether and how a gap between policy and practice is bridged.

Despite the analyses and recommendations presented in this article, the overarching issue of whether universalism is a sustainable approach to health equity remains. The balance of equality and equity is sensitive within universalism, where too much emphasis on equality can overlook intricate effects of equity, and likewise, too much focus on equity may overthrow the notion of equality altogether. Absolute equity is a utopian ideal, and Norway's universal welfare system will unavoidably result in some degree of inequity within the population, as universalism as a theory or policy aim is inherently limited by its collectivist nature. Notwithstanding this barrier, a balance between equity and equality could be achieved in Norway's health policy through the collaboration of service users, service providers and policymakers in reevaluating policy measures and devising a more nuanced application of universalism in accordance to the diversifying needs of contemporary Norwegian society.

\section{Acknowledgments}

First and foremost, I thank all the reviewers and editors involved in the revisions of this work for Social Inclusion for their valuable feedback. Furthermore, I extend my gratitude to my doctoral supervisors, Professor Trude Karine Olaug Gjernes at Nord University and Dr. Susan Young at the University of Western Australia for their continued guidance and assistance. Finally, I thank Dr. Jessica Allen Hanssen at Nord University for her input and proofreading of this article.

\section{Conflict of Interests}

The author declares no conflict of interests.

\section{References}

Anttonen, A., Haikio, L., \& Kolbeinn, S. (2012). The future of the welfare state: Rethinking universalism. In A. Anttonen, L. Haikio, \& S. Kolbeinn (Eds.), Welfare state, universalism and diversity (pp. 187-196). Cheltenham: Edward Elgar Publishing.

Anttonen, A., \& Sipilä, J. (2012). Universalism in the British and Scandinavian social policy debates. In A. Anttonen, L. Haikio, \& S. Kolbeinn (Eds.), Welfare state, universalism and diversity (pp. 16-41). Cheltenham: Edward Elgar Publishing.

Attanapola, C. T. (2013). Migration and health: A literature review of the health of immigrant populations in Norway. Trondheim: NTNU Social Research. Retrieved from https://samforsk.brage.unit. no/samforsk-xmlui/handle/11250/2365877

Carey, G., \& Crammond, B. (2017). A glossary of policy frameworks: The many forms of 'universalism' and policy 'targeting.' Journal of Epidemiology and Community Health, 71(3), 303-307. http://dx.doi.org/ 10.1136/jech-2014-204311

Carey, G., Crammond, B., \& de Leeuw, E. (2015). Towards health equity: A framework for the application of proportionate universalism. International Journal for Equity in Health, 14(1), 81. http://dx.doi.org/10.1186/ s12939-015-0207-6

Dahl, E. (2009). Health inequalities and health policy: The Norwegian case. Norsk Epidemiologi, 12(1), 69-75. https://doi.org/10.5324/nje.v12i1.521

Darj, E., \& Lindmark, G. (2002). Not all women use maternal health services. Language barriers and fear of the examination are common. Lakartidningen, 99(1/2), 41-44.

Dejin-Karlsson, E., \& Östergren, P.-O. (2004). Country of origin, social support and the risk of small for gestational age birth. Scandinavian Journal of Public Health, 32(6), 442-449. https://doi.org/10.1080/ 14034940410028172

Helsenorge. (2019). Pregnancy and maternity care in Norway. Helsenorge. Retrieved from https://helsenorge. no/other-languages/english/pregnancy-andmaternity-care

Helsesøstre. (2007). Jærstrendene-Manges helsekilde Helses $\varnothing$ stre [Public health nurses. Jærstrendende-A source for helath"] (Report No. 1-2007). Askim: Østfold Trykkeri AS. Retrieved from https://www.nsf.no/ Content/252225/HELSES_1_07.pdf

Kautto, M. (2010). The Nordic countries. In F. G. Castles, S. Leibfried, J. Lewis, H. Obinger, \& C. Pierson (Eds.), The Oxford handbook of the welfare state. Oxford: Oxford University Press.

Kuhnle, S., \& Hort, S. E. (2004). The developmental welfare state in Scandinavia: Lessons for the developing world. Geneva: United Nations Research Institute for Social Development.

Lipsky, M. (1980). Street level bureaucracy: Dilemmas of the individual in public services. New York, NY: Russell Sage Foundation.

Mehrara, L. (2017). Imperfections of a perfect state-A social policy analysis of the provisions of maternal health services for migrant women in Norway: A case study on Stavanger (Unpublished Master's dissertation). University of Stavanger, Stavanger, Norway. Retrieved from http://hdl.handle.net/11250/2450604

Munthe-Kaas, H. M., Bidonde, J., Nguyen, L., Flodgren, G., \& Meneses, J. (2018). Effect of health equity tools for immigrants: A systematic review. Trondheim: Norwegian Institute of Public Health. Retrieved from https://www.fhi.no/en/publ/2018/Effect-of-healthequity-tools-for-immigrants-a-systematic-review

Nørredam, M., \& Krasnik, A. (2011). Migrants' access to health services. In B. Rechel, P. Mladovsky, W. Devillé, B. Rijks, R. Petrova-Benedict, \& M. McKee (Eds.), Migration and health in the European Union (pp. 67-78). Maidenhead: Open University Press. 
Ny, P. (2007). Swedish maternal health care in a multiethnic society-Including the fathers (Unpublished Doctoral dissertation). Malmö University, Malmö, Sweden. Retrieved from https://muep.mau.se/handle/ 2043/4105

Rechel, B., Mladovsky, P., Devillé, W., Rijks, B., PetrovaBenedict, R., \& McKee, M. (Eds.). (2011). The future of migrant health in Europe. Maidenhead: Open University Press.

Reeske, A., \& Razum, O. (2011). Maternal and child health: From conception to first birthday. In B. Rechel, P. Mladovsky, W. Devillé, B. Rijks, R. PetrovaBenedict, \& M. McKee (Eds.), Migration and health in the European Union (pp. 139-154). Maidenhead: Open University Press.

Ringard, A., Sagan, N., Saunes, I. S., \& Lindahl, A. K. (2013). Norway: Health system review. Health Systems in Transition, 15(8), 1-162. Retrieved from https://apps. who.int/iris/handle/10665/330299

Shim, J. K. (2010). Cultural health capital: A theoretical approach to understanding health care interactions and the dynamics of unequal treatment. Journal of Health and Social Behavior, 51(1), 1-15. https://doi. org/10.1177/0022146509361185

Statistics Norway. (n.d.). Persons with immigrant background. Statistics Norway. Retrieved from https://www.ssb.no/ajax/ordforklaring?key=225102 \&sprak=en

Statistics Norway. (2019). Immigrants and Norwegianborn to immigrant parents. Statistics Norway. Retrieved from https://www.ssb.no/en/innvbef

Stavanger Kommune. (2016). TEGRA, svangerskapskurs og barselgruppe [TEGRA, childbirth course and maternity group]. Stavanger Kommune. Retrieved from http://www.stavanger.kommune.no/no/Tilbudtjenester-og-skjema/Barn-og-familie/Helsestasjon/ Gruppetilbud1/TEGRA

Stefánsson, K. (2012). What is in a word? Universalism, ideology and practice. In A. Anttonen, L. Haikio, \& S. Kolbeinn (Eds.), Welfare state, universalism and diversity (pp. 42-68). Cheltenham: Edward Elgar Publishing.

Vassenden, A. (2010). Untangling the different components of Norwegianness. Nations and Nationalism, 16(4), 734-752. https://doi.org/10.1111/j.14698129.2009.00438.x

Vike, H. (2018). Street-level bureaucracy and crosscutting cleavages in municipal worlds. In H. Byrkjeflot \& F. Engelstad (Eds.), Bureaucracy and society in transition: Comparative perspectives (pp. 245-263). Bingley: Emerald Publishing.

WHO. (n.d.). Equity. World Health Organization. Retrieved from http://www.who.int/healthsystems/ topics/equity/en

\section{About the Author}

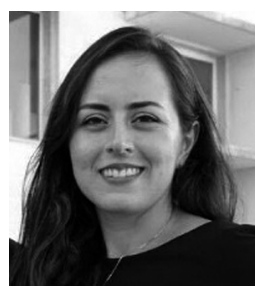

Lydia Mehrara is a PhD Candidate in Sociology at Nord University, Bod $\varnothing$, Norway. Her doctoral project examines the implications of Norway's decentralized approach to addressing the maternal health needs of immigrant women across the country. It applies a sociological perspective to the equity and equality debate within the context of universalism by focusing on maternal health services for immigrant women as a representation of this dynamic, from both the macro (system) and micro (individual) dimensions. 